\title{
PENGEMBANGAN MODEL PENYUSUNAN KURIKULUM TINGKAT SATUAN PENDIDIKAN (KTSP) YANG MENGACU PADA STANDAR NASIONAL PENDIDIKAN
}

\author{
Dr. Lely Halimah, M.Pd., Dra. R. Deti Rostika, M.Pd., Drs. Encep
} Sudirjo, M.Pd.

\begin{abstract}
Abstrak
his research is performed due to the presence of gap between the policy in the

$T$ improvement of curriculum and the existing field-condition in elementary school. On one side School-Based Curriculum (KTSP) is expected to be applied in schools autonomously, on the other hand, neither the principals nor the teachers, especially of elementary schools, have had comprehensive understanding on the concept of School-Based Curriculum, its construction process, as well as the implementation. The problem of this research, therefore, is "How is a model for the construction of School-Based Curriculum that refers to National Education Standard developed to result in School-Based Curriculum (KTSP) document"?

With reference to the above mentioned background, this research is purposed to offer facilities to schools, especially elementary schools, in the process of constructing School-Based Curriculum that refers to the guideline of KTSP construction by Badan Standar Nasional Pendidikan (National Standard Agency for Education), so that they can have KTSP document. In other words, this research will result in a product of the process of School-Based Curriculum (KTSP) model development for KTSP document.

In order to achieve the objectives, this research is conducted using Research and Development approach. In the implementation, this research and development forms a cycle, which begins with a preliminary study to find an early product required. This early product is then developed in a certain condition, with a test, the result of which is revised and retested until the final product, which is considered satisfactory, is obtained. The validity of this final product is then examined. This research is conducted in elementary schools in Cileunyi District of Bandung Regency, of which the principal and the teachers become the subject of this research.

Referring to the Research and Development measures, as mentioned above, the process of constructing School-Based Curriculum (KTSP) contains two stages. The first stage is the work discussion of the team that consists of Headmaster as the chairman, teachers, and school committee, and involves related parties from the Subdistrict Office of National Education Department and experts (in this case: the research team), which produces book 1 containing general guideline of School-Based Curriculum (KTSP) development. The second stage is the work discussion of the research team, Headmaster, and teachers, which produces book 2 consisting of six copies of books for each grade, from the first to the

Suggestions put forward in this research is that the socialization of School-Based Curriculum (KTSP) should be carried out in whole and applicable so as to give clear description of the process and product of School-Based Curriculum (KTSP) construction to those school, since they-elementary schools in particular- have not been able to create School-Based Curriculum (KTSP) autonomously.
\end{abstract} sixth.

Key Word: Pengembangan Penyusunan KTSP; Standar Nasional Pendidikan 


\section{LATAR BELAKANG MASALAH}

Dalam upaya peningkatan kualitas sumber daya manusia, pendidikan memegang peran yang sangat penting. Mengingat peningkatan kualitas pendidikan merupakan suatu proses yang terintegrasi dengan proses peningkatan kualitas sumber daya manusia itu sendiri. Menyadari pentingnya proses peningkatan kualitas sumber daya manusia, pemerintah terus berupaya melalui berbagai usaha pembangunan pendidikan yang lebih berkualitas antara lain melalui Undang-Undang No. 22 Tahun 1999 tentang Otonomi Daerah, Undang-Undang No. 20/2003 tentang Sistem Pendidikan Nasional, UndangUndang No.14/2005 tentang Guru dan Dosen, dan PP No. 19/2005 tentang Standar Nasional Pendidikan.

Terkait dengan dengan Undang-undang No. 22 Tahun 1999 tentang Otonomi Daerah dan Peraturan Pemerintah No. 25 Tahun 2000 Tentang Kewenangan Pemerintah dan Daerah Propinsi sebagai Daerah Otonom berimplikasi terhadap kebijakan pengelolaan pendidikan dari yang bersifat sentralis ke desentralistik. Pergeseran pengelolaan tersebut berimplikasi pula pada penyempurnaan kurikulum, yang pada dasarnya mengamanatkan bahwa kurikulum pada jenjang pendidikan dasar dan menengah disusun oleh satuan pendidikan dengan mengacu kepada Standar Kompetensi Lulusan (SKL) dan Standar Isi (SI) serta berpedoman pada panduan yang disusun oleh Badan Standar Nasional Pendidikan (BSNP).

Kurikulum Tingkat Satuan Pendidikan merupakan salah satu bentuk realisasi kebijakan desentralisasi di bidang pendidikan agar kurikulum benar-benar sesuai dengan kebutuhan pengembangan potensi peserta didik di sekolah yang bersangkutan di masa sekarang dan yang akan datang dengan mempertimbangkan kepentingan lokal, nasional dan tuntutan global dengan semangat manajemen berbasis sekolah.

Sejalan dengan dasar-dasar pemikiran di atas, bagaimana realisasinya di lapangan dalam hal proses penyusunan KTSP dan ketersediaan, kelengkapan dokumen KTSP yang fisibilitas sebagai wujud hasil kinerja kepala sekolah. Berdasarkan hasil studi pendahuluan, dalam proses penyusunan KTSP menurut beberapa kepala sekolah belum sejalan dengan yang diarahkan dalam panduan yang disusun BSNP. Begitu pula dokumen tertulis KTSP, pada umumnya sekolah belum memilikinya, baru sebatas kumpulan silabus dan rencana pelaksanaan pembelajaran yang dibuat oleh guru-guru. Bahkan kepala sekolah tampaknya masih belum memahami dengan baik prosedur yang harus dilakukan dalam penyusunan KTSP.

Gambaran kondisi lapangan ini, tentunya harus segera diatasi mengingat pemerintah mengharapkan bahwa standar isi dan standar kompetensi lulusan yang kemudian dioperasionalkan ke 
dalam KTSP dapat dilaksanakan mulai tahun pelajaran 2006/2007 dan selambat-lambatnya pada tahun 2009/2010. Sekolah boleh belum melaksanakan KTSP pada tahun pelajaran 2009/2010 dengaii izin dari Menteri Pendidikan Nasional. Sekolah yang sudah melaksanakan uji coba KBK/"Kurikulum 2004" secara menyeluruh dapat melaksanakan KTSP secara serentak pada seluruh tingkat kelas mulai tahun pelajaran 2006/2007 (Permen Diknas. No. 24 tahun 2006 pasal 2).

Mengacu pada harapan pemerintah dan kondisi lapangan sebagaimana dikemukakan di atas, maka melalui penelitian ini diharapkan dapat memfasilitasi sekolah-sekolah khususnya sekolah dasar dalam penyusunan KTSP secara mandiri sesuai dengan hasil analisi konteks.

\section{RUMUSAN MASALAH}

Sesuai dengan berbagai kebijakan tentang penyempurnaan kurikulum, dan realita yang ada di lapangan, maka yang menjadi permasalahan dalam penelitian ini, adalah bagaimana pengembangan model penyusunan KTSP yang mengacu pada tuntutan standar nasional pendidikan, sehingga menghasilkan dokumen KTSP yang dapat dijadikan pedoman dalam implementasi KTSP? Permasalahan ini dijabarkan ke dalam beberapa pertanyaan sebagai berikut.

1. Bagaimana kinerja kepala sekolah dalam pengembangan KTSP, dilihat proses penyusunan KTSP, kelengkapan dokumen KTSP, dan kendala-kendala yang dialaminya dalam penyusunan KTSP?

2. Bagaimana kerangka model proses penyusunan KTSP yang sesuai dengan kondisi lapangan dan mengacu pada panduan yang disusun oleh BSNP, agar menghasilkan dokumen tertusli KTSP yang sesuai dengan potensi sekolah dasar?

3. Bagaimana model final proses penyusunan KTSP yang relevan dengan kondisi lapangan serta mengacu pada panduan yang telah disusun oleh BSNP, sehingga menghasilkan dokumen tertulis KTSP yang relevan dengan potensi sekolah dasar?

\section{TUJUAN PENELITIAN}

Secara umum penelitian ini, bertujuan untuk meningkatkan pemahaman kepala sekolah dan guru-gusu sekolah dasar baik yang berkaitan dengan konsep KTSP dan proses pengembangannya yang meliputi perencanaan, penyusunan, dan implementasi KTSP. Prosedur kerja yang sistematis dalam pengembangan KTSP ini mengacu pada panduan yang dikembangkan oleh BSNP. Produk kegiatan ini adalah ketersediaan dan kelengkapan, serta fisibilitas dokumen tertulis KTSP pada jenjang sekolah dasar. Secara khusus tujuan penelitian ini adalah sebagai berikut. 
1) Melakukan analisis kebutuhan dilihat dari proses penyusunan KTSP, dokumen tertulis KTSP, dan kendala-kendalanya dalam rangka menemukan kerangka awal pengembangan model proses penyusunan dokumen tertulis KTSP jenjang sekolah dasar.

2) Mengembangkan kerangka model penyusunan KTSP yang sesuai dengan kondisi lapangan dan panduan yang disusun BSNP, agar menghasilkan dokumen KTSP yang sesuai dengan potensi sekolah dasar.

3) Menghasilkan model final proses penyusunan KTSP yang menghasilkan dokumen tertulis KTSP yang sesuai dengan potensi sekolah dasar dan fisibilitas.

\section{KERANGKA TEORETIS}

KTSP adalah kurikulum operasional yang disusun dan dilaksanakan oleh masing-masing satuan pendidikan (sekolah), dengan mengacu kepada standar kompetensi lulusan dan standar isi, serta berpedoman pada panduan yang disusun oleh BSNP. KTSP disusun sebagai pedoman penyelenggaraan kegiatan pembelajaran untuk mencapai tujuan pendidikan di tingkat satuan pendidikan. Dalam hal ini tujuan pendidikan dasar adalah meletakan dasar kecerdasan, pengetahuan, kepribadian, akhlak mulia, serta keterampilan untuk hidup mandiri dan mengikuti pendidikan lebih lanjut.

Badan Standar Nasional Pendidikan, telah memberikan arahan bagaimana pihak sekolah menyusun KTSP. Khusunya dalam mekanisme penyusunan KTSP yang dilakukan sekolah, yaitu sekolah harus menentukan tim penyusun KTSP yang terdiri dari kepala sekolah sebagai ketua merangkap anggota, guru, konselor, komite sekolah, dan nara sumber, serta dinas pendidikan setempat. Penyusunan KTSP pada dasarnya merupakan bagian dari kegiatan perencanaan sekolah/madrasah. Kegiatan ini dapat berbentuk rapat kerja dan/atau lokakarya sekolah/madrasah dan/atau kelompok sekolah/madrasah yang diselenggarakan dalam jangka waktu sebelum tahun pelajaran baru. Tahap kegiatan penyusunan KTSP secara garis besar meliputi penyiapan dan penyusunan draf, reviu dan revisi, serta finalisasi, pemantapan dan penilaian. Langkah yang lebih rinci dari masing-masing kegiatan diatur dan diselenggarakan oleh tim penyusun.

Adapun dalam pelaksanaannya tim penyusun KTSP ini, secara bersama-sama melakukan analisi konteks terlebih dahulu. Dalam hal ini, tim (1) mengidentifikasi standar kompetensi lulusan dan standar isi sebagai acuan dalam penyusunan KTSP, (2) menganalisis kondisi yang ada di satuan pendidikan yang meliputi peserta didik, pendidik dan tenaga kependidikan, sarana prasarana, biaya, dan programprogram, dan (3) menganalisis peluang dan tantangan yang ada di masyarakat dan lingkungan sekitar 
yang meliputi komite sekolah, dewan pendidikan, dinas pendidikan, asosiasi profesi, dunia industri dan dunia kerja, sumber daya alam dan sosial budaya.

Berdasarkan hasil analisis konteks tersebut, maka langkah selanjutnya sekolah dapat menentukan visi, dan misi sekolah, yang kemudian dijabarkan ke dalam berbagai program pendidikan, yang meliputi komponen-komponen berikut ini.

a. Tujuan pendidikan tingkat satuan pendidikan

b. Struktur dan muatan kurikulum (berisi mata pelajaran, muatan lokal, pengembangan diri, pengaturan beban belajaran, kriteria ketuntasan belajar, ketentuan mengenai kenaikan kelas dan kelulusan, pendidikan kecakapan hidup, pendidikan berbasis lokal dan global)

c. Kalender pendidikan

d. Lampiran-lampiran (yaitu program tahunan, program semester, silabus, RPP, SK dan KD mulok, program pengembangan diri, dan perangkat lainnya, misalnya pemetaan KD atau indikator).

Setelah komponen-komponen tersebut lengkap disusun oleh tim, maka dokumen kurikulum tersebut untuk pemberlakuannya yaitu oleh kepala sekolah setelah mendapat pertimbangan dari komite sekolah dan diketahui oleh dinas tingkat kabupaten/kota yang bertanggung jawab di bidang pendidikan untuk SD

\section{PROSEDUR PENELITIAN}

Metode yang digunakan dalam penelitian ini adalah penelitian dan pengembangan (Research \& Development). Dalam proses pelaksanaannya, penelitian dan pengembangan ini membentuk suatu siklus, yang dimulai dengan melakukan studi pendahuluan untuk menemukan kerangka produk awal yang dibutuhkan. Produk awal tersebut dikembangkan dalam suatu situasi tertentu, melalui suatu uji coba, yang hasilnya kemudian direvisi dan diuji coba kembali sehingga pada akhirnya ditemukan suatu produk akhir yang dianggap sempurna yang selanjutnya produk tersebut diuji validasinya.

Subjek penelitian ini adalah (a) kepala sekolah dasar, (b) guru-guru sekolah dasar, (c) komite sekolah, dan (d) pengawas TK/SD dari diknas kecamatan Cileunyi. Dari hasil studi pendahuluan diketahui jumlah SD yang ada di kecamatan Cilenyi sebanyak 50 SD yang dibina oleh 4 orang Pengawas TK/SD. Untuk kepentingan penelitian ini, dari 50 SD ditetapkan sampel sebanyak 20\% yaitu 10 SD. Dengan demikian, jumlah kepala sekolah yang menjadi sumber informasi sebanyak 10 orang, komite sekolah 10 
orang, dan guru dari setiap SD ditetapkan 2 orang, jadi guru yang menjadi sumber informasi 20 orang. Sementara pengawas TK/SD semuanya (4 orang) dijadikan sumber informasi.

Teknik analisis data dalam penelitian ini dilakukan secara deskriptif kualitatif, yaitu data dianalisis berdasarkan pemikiran rasional dan penalaran logis, melalui asumsi-asumsi dan teori-teori yang dikaji. Menurut Maleong (Sanjaya, 2006) dalam penelitian kualitatif, analisis dan penafsiran data merupakan proses yang tidak dapat dipisahkan. Oleh karena itu, dalam penelitian ini analisis data dilakukan secara bersama-sama dan terus-menerus sampai berhasil menemukan model dokumen KTSP. Langkah-langkah yang dilakukan dalam proses analisis dan penafsiran data kualitatif adalah sebagai berikut.

1. Menelaah seluruh data yang tersedia dari berbagai sumber data baik hasil wawancara, kuesionar, maupun observasi.

2. Membuat abstraksi atau membuat rangkuman dari hasil analisis dan penelaahan data dari setiap sumber dan dan teknik pengumpulan data yang digunakan.

3. Menyusun satuan-satuan atau kategorisasi data sesuai dengan pokok permasalahan yang dipertanyakan.

4. Mengadakan pemeriksaan keabsahan data dengan membandingkan hasil-hasil dari setiap teknik yang digunakan (trianggulasi)

\section{HASIL PENELITIAN}

\section{Data Empirik Kondisi Lapangan dalam Pengembangan KTSP}

Dilihat dari pemahaman kepala sekolah dan guru-guru terhadap KTSP, pada umumnya mereka belum memahami dengan baik. Walaupun mereka sudah mendapatkan informasi dari berbagai sumber baik melalui kegiatan seminar maupun dari sumber-sumber lainnya seperti dari berbagai media cetak, dan dari Diknas setempat, tetapi pada umumnya menurut mereka KTSP itu masih abstrak, sehingga bingung untuk memulainya. Sejalan dengan kurangnya pemahaman para kepala sekolah terhadap KTSP, maka dari 10 sekolah yang menjadi responden pada umumnya mereka belum dapat menyusun KTSP secara mandiri. Terkait dengan adanya panduan penyusunan KTSP yang dikeluarkan oleh BSNP, pada umumnya baik kepala sekolah maupun guru-guru sekolah dasar belum pernah membacanya.

\section{Pengembangan Model Dokumen KTSP}


Pengembangan model merupakan proses kegiatan penyusunan KTSP yang diharapkan menghasilkan suatu produk yaitu berupa dokumen tertulis KTSP sebagai kurikulum ideal yang dapat dijadikan panduan dalam implementasi KTSP oleh sekolah. Kegiatan pengembangan model dilakukan untuk memfasilitasi sekolah dalam menyusun dokumen KTSP dengan mengacu pada langkah-langkah sebagaimana yang dikemukakan BSNP dalam mengembangkan KTSP. Untuk menghasilkan dokumen tertulis KTSP (KTSP ideal) dalam hal ini dilakukan melalui tahapan-tahapan berikut ini.

a. Penyusunan draf awal model dokumen KTSP

Penyusunan draf awal model dokumen KTSP yaitu berupa pemetaan kerangka isi dokumen KTSP yang akan dikembangkan. Draf ini disusun oleh tim peneliti, dengan mengacu pada hasil kajian literatur dan studi lapangan. Hasil darf awal yang telah dikembangkan oleh tim peneliti ini dijadikan bahan diskusi dengan kepala sekolah dan guru-guru, serta komite sekolah.

Draf awal dokumen KTSP tersebut merupakan produk awal yang akan digunakan sebagai acuan dalam musyawarah kerja kepala sekolah dengan semua elemen yang berkepentingan dalam penyusunan KTSP, yang dalam hal ini melibatkan kepala dinas tingkat kecamatan dan para pengawas, guru-guru SD tersebut, komite sekolah, dan tim ahli peneliti. Pada tahap ini dilakukan musyawarah kerja sebagaimana yang diarahkan oleh BSNP. Adapun langkah-langkahnya adalah sebagai berikut.

Langkah pertama adalah analisis konteks sekolah, dengan prosedur kerja sebagai berikut ini.

1) Tim bersama kepala sekolah dan guru-guru mengidentifikasi sumber-sumber yang relevan untuk dijadikan acuan dalam penyusunan KTSP, sehingga menghasilkan draf awal dokumen KTSP.

2) Tim mengadakan koordinasi dengan kepala sekolah, guru-guru, komite sekolah, dan dinas tingkat kecamatan, dan tenaga ahli yang relevan untuk mengkaji draf awal dokumen KTSP.

3) Dalam kegiatan musyawarah kerja, tim sesuai dengan kapasitas masing-masing melakukan analisis konteks yang meliputi kegiatan berikut ini.

a. Mengidentifikasi SKL dan SI sebagai acuan dalam penyusunan KTSP.

b. Menganalisis kondisi yang ada di satuan pendidikan yang meliputi peserta didik, pendidik dan tenaga kependidikan, sarana prasarana, biaya, dan program-program.

c. Menganalisis peluang dan tantangan yang ada di masyarakat dan lingkungan sekitar: komite sekolah, dewan pendidikan, dinas pendidikan, asosiasi profesi, dunia industri dan dunia kerja, sumber daya alam dan sosial budaya.

4) Hasil analisis konteks tersebut dituangkan dalam draf dokumen KTSP yang telah disusun, yang kemudian dijadikan dasar acuan dalam menentukan visi, misi, dan tujuan pendidikan. 
5) Produk dari kegiatan musyawarah kerja yaitu menghasilkan dokumen KTSP yang diberi judul buku 1 pedoman umum pengembangan KTSP. Dalam buku ini terdiri atas lima bagian atau bab yang secara rinci meliputi bagian 1 landasan dan prinsip, dan acuan operasional Standar Kompetensi Lulusan (SKL), bagian 2 berisi rumusan visi, misi dan tujuan sekolah, bagian 3 berisi struktur dan muatan KTSP, bagian 4 berisi standar kompetensi lulusan setiap mata pelajaran, dan bagian 5 berisi pedoman pelaksanaan penyusunan silabus dan Rencana Pelaksanaan Pembelajaran (RPP).

Langkah kedua, setelah dilakukan musyawarah kerja pada tahap pertama, langkah selanjutnya adalah musyawarah kerja guru, yang dipimpin oleh kepala sekolah dan dipandu oleh tim peneliti, dengan prosedur kerja sebagai berikut.

1) Tim melakukan koordinasi dengan kepala sekolah untuk membentuk kelompok kerja guru bidang studi dan guru kelas;

2) Tim memberikan inspirasi untuk menstimuli harapan-harapan guru dalam penyusunan pedoman operasional dan silabus untuk masing-masing bidang studi dan kelas, sehingga dihasilkan draf awal pengembangan pedoman operasional dan silabus;

3) Tim secara berkolaborasi dengan guru-guru mengadakan musyawarah kerja dalam menyusun pedoman operasional dan silabus untuk masing-masing bidang studi dan kelas dengan mengacu pada panduan umum hasil musyawarah kerja pertama.

4) Produk dari hasil musyawarah kerja ini adalah buku 2 yang diberi judul Panduan Operasional Pengembangan KTSP Tingkat Kelas. Isi buku meliputi dua bagian yaitu bagian pertama berisi panduan umum pelaksanaan pembelajaran dan penilaiannya, dan bagian dua berisi silabus untuk masing-masing bidang studi dalam lingkup kelas, sehingga menjadi 6 eksemplar atau buku (KTSP kelas 1 sampai dengan kelas 6).

Produk pengembangan KTSP hasil musyawarah kerja ini adalah 1 eksplar buku yang berisi panduan umum pelaksanaan KTSP dan 6 eksemplar buku yang masing-masing berisi panduan operasional pelaksanaan pembelajaran dan silabus untuk masing-masing kelas (kelas 1 - kelas 6). Ketujuh eksemplar buku tersebut dirancang untuk dijadikan acuan atau pedoman umum dalam pelaksanaan kurikulum, yang diperuntukkan khususnya untuk guru-guru dalam mengembangkan program-program pembelajaran dan pelaksanaan proses pembelajaran. Sementara bagi kepala sekolah dapat digunakan sebagai acuan baik dalam mengembangkan program lebih lanjut, melaksanakan program dan evaluasi program. Secara umum, tentunya ketujuh buku tersebut harus digunakan sebagai alat atau instrumen untuk mencapai tujuan pendidikan sebagaimana yang diharapkan sekolah. 
a. Uji Coba Model

Dokumen KTSP sebagai produk pengembangan model yang dilakukan melalui musyawarah kerja ini, sebelum disosialisasikan kepada para pengembang kurikulum terutama guru-guru sekolah dasar, perlu dilakukan uji coba terlebih dahulu. Tahap uji coba ini dilakukan pada sampel terbatas yaitu hanya beberapa orang kepala sekolah dan guru untuk mengkaji dokumen KTSP hasil pengembangan. Fokus kajian lebih diarahkan pada penilaian terhadap isi dokumen KTSP, yang meliputi pengembangan topik dokumen KTSP, pengorganisasian isi dokumen KTSP, serta keterbacaan dan kebahasaannya.

b. Uji Validasi Model Dokumen KTSP

Uji validasi dilakukan terhadap isi dokumen KTSP ini bertujuan untuk melihat sejauhmana tingkat keterpahaman kepala sekolah dan guru terhadap isi dokumen KTSP yang telah direvisi sesuai hasil uji coba. Fokus kajian pada dasarnya sama dengan pada kegiatan uji coba, akan tetapi dalam pelaksanaannya dilakukan pada skala yang lebih luas dengan tujuan untuk memperoleh masukan yang lebih banyak dan lebih komprehensif dalam setiap bagiannya. Hasil uji validasi dokumen KTSP ini selanjutnya digunakan untuk dasar penentuan model final dokumen KTSP yang siap didesiminasikan.

\section{Model Final Dokumen KTSP Hasil Pengembangan}

Model final dokumen KTSP hasil pengembangan yaitu sebagaimana telah dikemukakan di atas terdiri atas tujuh buku atau eksemplar, yaitu 1 eksemplar tentang pedoman umum pengembangan KTSP dan enam eksemplar untuk masing-masing kelas dari kelas satu sampai dengan kelas enam. Setiap eksemplar berisi uraian-uraian sebagaimana dikemukakan berikut ini.

Buku 1 Pedoman Umum Pengembangan KTSP, memuat isi di antaranya adalah sebagai berikut.

a. Halaman Pengesahan, halaman ini berisi pernyataan dari kepala sekolah tentang diberlakukannya KTSP, yang kemudian dibubuhi tanda tangannya. Pernyataan diberlakukannya KTSP tersebut, kemudian diketahui oleh pihak Depdiknas Tingkat Kecamatan Kabupaten Bandung yang dibubuhi oleh tanda tangannya, juga diketahui oleh komite sekolah yang dibuktikan dengan adanya tanda tangan dari komite tersebut.

b. Kata Pengantar, merupakan paparan isi buku secara garis besarnya yang disertai dengan ucapan terima kasih dari pihak kepala sekolah bagi semua pihak yang telah membantu mewujudkan dokumen KTSP untuk sekolah tersebut. 
c. Daftar Isi, memberikan gambaran berkenaan dengan isi dokumen tersebut, yang salah satu fungsinya untuk memberikan kemudahan dalam menemukan bagian-bagian yang diperlukan untuk membacanya.

Sedangkan buku dua yang terdiri dari enam eksplar atau buku berisi panduan operasional pelaksanaan KTSP, dikembangkan untuk masing-masing kelas yaitu dari kelas 1 sampai dengan kelas 6 . keenam kelas ini dikelompokkan menjadi kelompok kelas rendah (kelas 1,2, dan 3), dan kelompok kelas tinggi (kelas 4,5, dan 6). Untuk itu dalam bagian-bagian tertentu terdapat perbedaan terutama dalam arahan untuk pembelajaran tematik dan pembelajaran yang lebih konsentrasi pada pembelajaran mata pelajaran.

Dari keseluruhan isi dokumen KTSP tersebut, dilihat dari jumlah halamannya pada buku satu yaitu pedoman umum pengembangan KTSP menjadi sekitar 175 halaman. Sementara jumlah halaman pada buku dua yang terdiri dari tujuh eksempar, setiap eksemplarnya berkisar antara 175 sampai dengan 180 halaman. Dokumen KTSP untuk kelas rendah (kelas 1,2, dan 3) dan kelas tinggi (4,5, dan 6) terdapat perbedaan yang khas di antara kedua tingkatan tersebut, dalam hal ini KTSP kelas 1-3 SD menggunakan model kurikulum tematik, sementara KTSP kelas tinggi mengacu pada pengembangan kurikulum mata pelajaran

\section{DAFTAR PUSTAKA}

Badan Standar Nasional Pendidikan (2006). Panduan Penyusunan KurikulumTingkat Satuan Pendidikan Jenjang pendidikan Dasar dan Menengah. Jakarta. Depdiknas.

Hasan, S. Hamid. (1988). Evaluasi Kurikulum. Jakarta: Depdikbud.

Hanafie Imam. (2007). Plus Minus Kurikulum Tingkat Satuan Pendidikan. [Online). Tersedia: http//www. mahanive@yahoo.com

Ibrahim dan Karyadi, Beny. (1990). Materi Pokok: Pengembangan Inovasi dan Kurikulum. Jakarta: Depdikbud.

Jalal, Fasli \& Supriadi, Dedi. (2001). Reformasi Pendidikan dalam Konteks Otonomi Daerah. Yogyakarta: Depdiknas-Bappenas-Adicita Karya Nusa.

Longstreet, Wilma S \& Shane, Harold G. (1993). Curriculum for a New Millennium. Boston: Allyn and Bacon.

Mulyasa, E. (2003). Kurikulum Berbasis Kompetensi: Konsep, Karakterstik, dan Implementasi. Bandung: Remaja Rosdakarya.

Mulyasa, E. (2006) Kurikulum yang Disempurnakan: Pengembangan Standar Kompetensi dan Kompetensi Dasar. Bandung: Remaja Rosdakarya.

Nasution, S. (1991). Pengembangan Kurikulum. Bandung: Citra Aditya Bakti.

Oliva, Peter F. (1992). Developing the Curriculum. United States of America: HarperCollinsPublishers.

Peraturan Menteri Pendidikan Nasional Nomor. 22 Tahun 2006 tentang Standar Isi Untuk Satuan Pendidikan Dasar dan Menengah. 
Peraturan Menteri Pendidikan Nasional Nomor 23 Tahun 2006 tentang Standar Kompetensi Lulusan untuk Satuan Pendidikan Dasar dan Menengah.

Pusat Kurikulum (2007). Model Penilaian Kelas Kuriikulum Berbasis Kompetensi. [Online). Tersedia:http://www.Puskur. Net.

Sanjaya, Wina. (2005). Pembelajaran dalam Implementasi Kurikulum Berbasis Kompetensi. Jakarta: Prenada Media.

Sinclair, Robert L.(2003). Menggagas Kurikulum: Mencari Pijakan. Yogyakarta: UNY.

Soehendro, Bambang. (2006). Kurikulum KTSP. [Online). Tersedia: http://ktsp.jardiknas.org/

Sukmadinata, Nana Syaodih. (1997). Pengembangan Kurikulum: Teori dan Praktek. Bandung PT Remaja Rosdakarya.

Sumantri, Mulyani. (1988). Kurikulum dan Pengajaran. Jakarta: Depdikbud.

Tim Broad Based Education \& Depdiknas (2002). Pendidikan Berorientasi Kecakapan Hidup (Life Skill) Melalui Pendekatan Pendidikan Berbasis Luas Broad Based Education (BBE). Jakarta: Tim Broad Based Education; Depdiknas.

Yulaelawati, Ella. (2004). Kurikulum dan Pembelajaran: Filosofi Teori dan Aplikasi. Jakarta: Pakar Raya. 